\title{
Impact of Transformational Leadership on Job Satisfaction and Patient Safety Outcomes in Health Sector of Pakistan
}

\author{
Benish Khanzada1, Shahzad Naeem ${ }^{2 *}$ and Hashim Butt \\ ${ }^{1}$ National University of Medical Sciences, Pakistan \\ ${ }^{2}$ Riphah International University, Islamabad, Pakistan \\ ${ }^{3}$ Combined Military Hospital, Medical College, Lahore, Pakistan
}

\begin{abstract}
Background: To improve the patient safety among health care sector and organizations need effective and efficient leadership at all stages.

Purpose: The aim of this research was to examine the impact of nurse's manager transformational leadership performance on job contentment and also towards patient safety outcomes.

Methods: Random sampling of critical care nurses $(\mathrm{N}=358)$ was carried out through cross sectional survey in Lahore, Rawalpindi and Islamabad hospitals of Pakistan. By using structural equation model technique hypothesized model was verified.

Discussion: Data acceptability fit in the hypothesized model. Results highlighted that transformational leadership had solid positive impact on workstation empowerment, which resultantly enhances nurse's job satisfaction and reduces adverse patient outcomes frequency. Consequently, job satisfaction was interrelated towards lower adverse measures.

Conclusion: Findings of this research provides support for manager's to adopt transformational leadership conduct as a beneficial strategy to create office environments which encourage better safety results for patients as well as nurses.
\end{abstract}

Keywords: Transformational leadership; Patient safety; Job satisfaction; Empowerment; Work environment

\section{Introduction}

Worldwide patient safety and care quality are acknowledged as a priority for all organizations dealing health care. Though, large researches across Europe and North America have highlighted that health care organizations are liable to mistakes and the hazard of adversarial happenings is substantial [1,2].

Adversarial patient outcomes or happenings are described as unintentional injuries or problems affected by management of health care rather than original patient's ailment process, causing extended stay in hospital, disability or expiry [3]. According to landmark report of Institute of Medicine (IOM), every year in the United States due to human errors estimated 98,000 patients expire and due to avoidable medical mistakes approximately one million are injured [2]. Similarly, according to report of Canadian Institute for Health Information (CIHI) in Canada during 2014 and 2015 in more than 138,000 estimated hospitalizations, around 30,000- or one among every 18th patient underwent avoidable injury that conceded their care [4]. Research has highlighted that economic expenses of adverse events are also noteworthy and the load on developed countries rests high. For example, in 2009 and 2010 price of adverse happenings towards health care system of Canada was estimated around \$1.1 billion [5]. In United States also similar expenditures have been stated. After IOM report and past 18 years progress, patient safety remains a significant challenge in public health sector [6]. Previous researches highlighted that disturbingly in hospitals adverse events high rates are outcome of avoidable incidents, few of which are probably due to nursing associated issues [7]. Scholars have associated outcomes of patient safety with quality of nursing working environment and nonexistence of effective and efficient leadership [7]. In organizational literature, transformational leadership style has been linked with reduction in adverse patient results [8]. However, few researches have explored the mechanisms by which leadership affects employee performance which subsequently influence outcomes of patient's safety [9]. In the background of previous research work, one of the major knowledge gaps is how leadership in nursing trade and workplace features effect safety outcomes and quality of health care. Therefore, aim of this research was to examine a model connecting structural empowerment and transformational leadership towards nurse's job gratification and frequency of adverse happenings in severe care situations. In this research, it has been examined how transformational leadership impact towards job satisfaction and outcome of patient's safety and, structural empowerment as mediator.

Transformational leadership is performance based approach with aim to achieve performance beyond basic employee's potential and to struggle for brilliance [10]. Researches have highlighted that transformational leadership is vital in building helpful working environment for nurses in whom they are organizationally empowered for provision of optimum patient care [11].

Numerous authors [12] have recommended that style of

${ }^{*}$ Corresponding author: Shahzad Naeem, National University of Medical Sciences, Pakistan, Tel: +00923335491914; E-mail: shahzadflyer@yahoo.com

Received March 07, 2018; Accepted March 25, 2018; Published April 03, 2018

Citation: Khanzada B, Naeem S, Butt H (2018) Impact of Transformational Leadership on Job Satisfaction and Patient Safety Outcomes in Health Sector of Pakistan. J Health Educ Res Dev 6: 251. doi: 10.4172/2380-5439.1000251

Copyright: () 2018 Khanzada B, et al. This is an open-access article distributed under the terms of the Creative Commons Attribution License, which permits unrestricted use, distribution, and reproduction in any medium, provided the original author and source are credited. 
transformational leadership appears to be predominantly relevant in existing turbulent and nerve-wracking health care work atmospheres. Relating transformational leadership concept to this matter may offer awareness into the methods by which leadership can affect patient outcomes.

\section{Theoretical framework and relevant research}

This research integrates ideas from Bass theory of transformational leadership [13] and structural empowerment theory by Kanter [14] to study how workplace features effect job satisfaction and outcomes towards patient safety. Theoretical foundations of the thoughts in the suggested model are described in following paragraphs.

\section{Transformational leadership}

One of relational leadership style is transformational leadership in which employers have faith and admiration for their leadership and they are motivated for doing more than what is officially expected from them to attain organizational objectives [13].

Transformational leadership entails four basic dimensions: (1) Idealized inspiration (traits and actions) defines a manager for followers as an example or role model, establishes high conduct standards and he has capability to communicate organizational vision in struggle to win employees trust. (2) Inspirational enthusiasm reveals leader's clear expression of a convincing visualization through arguments, cryptograms, and descriptions [13] to inspire employees for their performance. (3) Intellectual inspiration, reflects the degree to which leader implores workers perspective on issues and took into consideration a diverse variety of ideas during decision making [13]. (4) Transformational leadership reflects leaders which involve themselves in individualized consideration; address individual variances employee's needs and pursue to counsel them in a struggle to assist them in reaching their full capabilities and potential [15].

Transformational leadership style has steadily been connected to employee behaviors, conduct and attitudes in both nursing and management backgrounds. Researchers are of the view that four ways of transformational leadership may help as experience in making working environment organizationally empower. For example, through intellectual inspiration, transformational leaders inspire employees to contribute in the process of decision making, which nurtures skills improvement, knowledge and critical thinking. Such leadership generates authorizing and empowering environments for nurses by affecting support quality, availability of resources at place of work and information. Behavior of transformational leaders is normally related with greater levels of workers satisfaction [16], performance of organization, work commitment of the followers [17], and workers enthusiasm to perform beyond than he was required for achieving assigned goal. In a research carried out on almost 700 nurses working in seven Canadian critical care hospitals, from Squires et al. [18] established significant association between job satisfaction and transformational leadership conduct of nurse working as managers. In recent times, [19] established that leaders with transformational can enhance patient care quality by ensuring citizenship behaviors at organizational level and caring practice environment. These researches elaborated the significance of transformational leadership style in generating work atmospheres that augments professional practices by nurse's practice which resultantly encourage improved results for nurses and patients. Transformational leaders after developing positive interactions and relationship obtain followers trust faith and forestall their requirements by giving accessibility to structural authorizing factors (i.e., support, information, resources) essential for workers to complete their work in a better way.

\section{Structural empowerment}

Structural empowerment theory by Kanter [14] enlightens the ways by adopting which leaders can have impact on workers regarding completion their assigned task successfully by ensuring access to four structures of organization: resources, information, opportunities support, Informational access is regarding to have organizational objectives knowledge, technical as well as policies knowledge and proficiency required for effectiveness at job. Support access comprises of supervision and response delivered by subordinates, peers and supervisors. It also includes emotional and social support from associates. Resources access refers having supplies, materials, time, equipment and money required to accomplish assigned task. Lastly, opportunities access refers to growth, mobility and involves challenge's access, competence recognition, rewards for skills, increased status and professional growth prospects that enhances one's skills and information $[14,20]$.

Various researches have been carried out to examine the theory of structural empowerment by Kanter in a diversity of nursing settings and populations. Structural authorization has been linked with hospital management features, for example greater stages of nurse independence and healthier relationships with physicians [21]. While working in empowering atmospheres, nurses have mutual support and sufficient resources needed for higher quality patient care [21] Structural empowerment has emerged as an important predictor for greater job satisfaction in nursing profession $[22,23]$.

Work commitment [24] organizational faith and obligation [25] turnover intents [26] and improvement in quality care [27].

Researchers recommended that nurses having transformational leadership traits may have increased organizational empowerment which lead towards improvement in working environments and outcomes of high-quality $[28,29]$.

\section{Adverse patient outcomes}

The main worry of any health care delivery method, and in principle nursing, is in achieving best patient results [30]. Researches related to patient outcome has endorsed that most adverse patient results to issues in work atmosphere [31] and deficiency in visible, efficient and effective leadership [2].

Aiken et al. [32] established that poor working environments and insufficient nursing staff were adverse patient results predictors, for example pneumonia, medication mistakes, pressure ulcers, rescue failure and humanity. In succeeding sub investigation of Canadian statistics from this research, similar outcomes were stated [28]. In this research, nurse evaluated adverse patient results or happenings comprises medication mistakes, patient drops, infections developed from hospital, pressure ulcers, and /or family complaints as perceived by nurses not from supervisory or administrative databank sources. Nurse care quality ratings offer related yet different patient outcomes information because nurses are almost involved at all patient care points, which create their viewpoint a valued informational source. In a research of 396 U.S. hospitals of 16,000 nurses [33] Established that nurse evaluated pat [26] care quality was related with indicators of objective hospital excellence, such as patient contentment, rescue failure and rates of mortality advising that real and nurse professed patient outcomes evaluation are intertwined. 


\section{Job satisfaction}

One of vital nursing outcome is job satisfaction, which is pretentious by work atmosphere quality. Even though the large number of research work which has been conducted on higher job dissatisfaction levels and job contentment, between nurses still continue $[34,35]$. Large number of researches has associated the nurses work atmosphere quality and their job satisfaction $[23,26]$. It was established that work environment characteristics, balanced job load, pace, associations with workmates, professional openings, and capability in meeting patients' requirements effects job satisfaction. Researchers [22,36] have presented strong positive association between job satisfaction amongst nurses and structural empowerment. Nurses' job satisfaction is serious for meeting quality results, patient contentment, and nurses retention in hospitals $[22,34,37]$. Though it is recognized that efficient nursing leadership is the driving strength in healthy work atmosphere creation that raises encouraging nurse and patient results, few empirical researches have been conducted which clearly defined and identified indirect and direct mechanisms by applying which leaders effectively changes in persons and patient results. This research work draws from research and theory to suggest a theoretical model connecting workplace empowerment and transformational leadership and, consequently, to job satisfaction of nurses and nurses evaluated adverse patient results.

\section{Hypothesized model}

Hypothesized model explains the proposed relations are represented in Figure 1. Largely, it is assumed that higher manager's transformational leadership staff ratings would be linked to greater organizational empowerment (hypothesis 1), which resultantly, would add in job satisfaction (hypothesis 2), and lesser adverse happenings (hypothesis 3). Greater job contentment would lead towards lesser adverse patient results (hypothesis 4).

\section{Methods}

\section{Design and sample}

For testing hypothesized model, cross-sectional predictive survey design was adopted. For this research random data of registered nurses $(n 1 / 41,000)$ employed in direct patient care in critical care hospitals around Rawalpindi, Islamabad was selected. A total of 358 nurses answered to the questionnaire with a response rate of $37 \%$. Qualified participants were only nurses employed in direct patient care environments. After gaining ethics endorsement, participants were dispatched a survey package on their residential address, including information letter, a questionnaire, along with prepaid envelope having postal address. Respondents were given two choices for participating in research firstly by filling a questionnaire or using online survey. Using

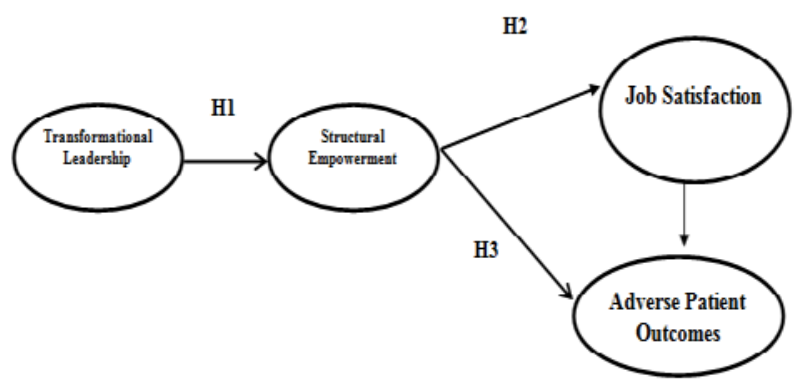

Figure 1: Conceptual Framework of the Study. method of Dillman et al. [38] to enhance response rates, responders who have not replied were issued a reminder after 3 weeks of initial letter.

\section{Measures}

Transformational leadership: Five dimensions of transformational leadership, idealized influenced behaviors (five items), idealized influenced attributes (four items), inspirational motivation (four items), individualized consideration (four items) and intellectual stimulation (four items) were measured by Multifactor Leadership Questionnaire5X. Participants assessed items on a five point Likert scale ranging from

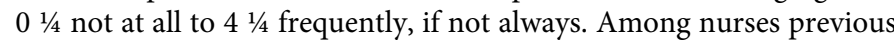
studies has supported the validity and reliability [39] (Cronbach a $1 / 4$ 0.74e0.87) [40]. In this research, the Cronbach a coefficient was 0.96 .

Structural empowerment: Conditions of Work EffectivenessII (CWEQ-II) a 12-item measure which contains four core subscales (resources, information, opportunity and support) [20] which highlights work empowerment structures dimensions. Each subscale consisted of $3 \mathrm{x}$ items which were assessed on a five-point scale ranged from $1 \frac{1 / 4}{4}$ none to $5 \frac{1}{4}$ a lot, be an average of creating subscale scores. After summing means of four subscales, total empowerment score was measured ranging from 4 to 20 . Overall higher scores highlight higher construction of empowerment perceptions. Internal consistency acceptability was reported, for evidenced Cronbach ranged from 0.74 to 0.89 in researches carried between period ranging from 1996 to 2013 [20,41]. Construct validity was recognized by use of (CFA) Confirmatory Factor Analysis [20,42].

For this research, adequate Cronbach alpha reliabilities were $(0.70$ e 0.82 ) and for subscales and overall scale (0.82).

Nurse-assessed adverse patient outcomes: By using an instrument developed by Sochalski [32] staff nurses' ratings regarding adverse patient results were measured and derived from Nursing Quality Indicators framed by [42]. Scale was comprised of $5 \mathrm{x}$ items which measured nurses' perceptions regarding incidence of common adverse patient results or difficulties faced during past year. Nurses were requested to rate occurrence frequency of specific adverse happenings (medication mistake, patient drops with injuries, after admission pressure ulcers, infections related to health care, and patient/family complaints), which happened within past year on scale measuring from 1 (never) to 4 (frequently). By carrying out average of five items overall score was calculated. In research of nurses working in Canadian hospital Cronbach alpha coefficients of 0.73 [28] and 0.80 [41] were found, which was within acceptable limits. Acceptable validity was presented by this scale $[32,43]$. In this research, scale reliability was found 0.78 .

Job satisfaction: By using Global Job Satisfaction (GJS) questionnaire Job satisfaction was calculated adapted from Job Diagnostic Survey by Hackman [44]. The GJS consisted on 4x items global measure for respondents satisfaction with regarding their and coworkers jobs. Respondents evaluated items on a five-point Likert scale, with 1 (strongly disagree), as lowest score and 5 (strongly agree), as highest score regarding job satisfaction. For nursing populations GJS survey was used and revealed internal consistency reliability within acceptable limits of 0.76 and 0.83 [23,45]. In present research, Cronbach was found 0.84 .

Data analysis: Using statistical package for social science, version 22.0 software descriptive statistics and scale reliabilities were evaluated (SPSS Inc., Chicago, IL) [46]. Before carrying out test of hypothesized 
model, preliminary CFA regarding factor structure of all measures was carried out by means of structural equation modeling (SEM) analysis in AMOS (version 21.0), SPSS Inc [47]. SEM with maximum likelihood estimation was used for testing fit between data and hypothesized model. To evaluate the importance of indirect effects upon model, keeping in view the greater statistical power in small samples biascorrected bootstrapping method with 1,000 iterations was carried out and reasonable control over type 1 error rate was maintained [48].

Recommendations of Lin and Hsieh, [49] were used for assessing model fit: chisquare (c2), chi-square/degrees of freedom, incremental fit index (IFI), comparative fit index (CFI) [50]. Tuckere Lewis index (TLI) [51] and root mean square error of approximation (RMSEA) [50]. For IFI and CFI generally agreed on critical value is 0.90 or higher. Meanings of perfect fit are that there is no difference between hypothesized and the observed model. Lack of fit between data and model was measured by RMSEA and values less than 0.05 indicates model is good fitting [52].

\section{Results}

\section{Participant characteristics}

Sample demographic characteristics were shown in Table 1. On the average nurses age was around 42 years with nursing experience of 20 years and 10 years working in current hospital unit. Mostly nursing staff was females (90\%), and (31\%) worked full time in medical surgical units and (31\%) in critical care units Overall, features of this research cohort are somewhat alike to those reported regarding all Ontario nurses [4].

\begin{tabular}{|c|c|c|}
\hline Demographic Characteristic & Mean & SD \\
\hline Age & 42 & 11.3 \\
\hline \multirow[t]{2}{*}{ Years of nursing experience } & 20 & 11.9 \\
\hline & $n$ & $\%$ \\
\hline \multicolumn{3}{|c|}{ Gender } \\
\hline Female & 336 & 90 \\
\hline Male & 22 & 10 \\
\hline \multicolumn{3}{|c|}{ Highest level of nursing education } \\
\hline College nursing diploma & 168 & 46.9 \\
\hline Bachelor degree in nursing & 166 & 46 \\
\hline Master's degree in nursing & 20 & 5.5 \\
\hline $\mathrm{phD}$ & 4 & 1.1 \\
\hline \multicolumn{3}{|c|}{ Current employment status } \\
\hline Full-time & 248 & 69 \\
\hline Part-time & 85 & 23 \\
\hline Casual & 25 & 6.9 \\
\hline \multicolumn{3}{|c|}{ Specialty of current unit } \\
\hline Medical-surgical & 110 & 30.7 \\
\hline Critical care & 110 & 30.7 \\
\hline Maternal-child & 33 & 9.2 \\
\hline Mental health & 8 & 2.2 \\
\hline Geriatric/rehabilitation & 7 & 1.95 \\
\hline Other/float resource unit & 90 & 25.1 \\
\hline \multicolumn{3}{|c|}{ Note: SD; standard deviation. } \\
\hline
\end{tabular}

\section{Descriptive results for major study variables}

Table 2 highlights means, Standard Deviations (SDs), and Cronbach reliabilities for research variables. On average, moderate degree of transformational leadership was reported among nurses managers (X $1 / 4$ 2.03; SD $1 / 4$ 0.97). Overall access to working environment factors that empower the nurses to work efficiently was a little above the midpoint scale (X 1/4 11.90; SD 1/4 3.76; range, 4e21). Past year, nurses described that (36\%) patient / family complaints and (28\%) nosocomial infections happened intermittently too regularly. Averagely nurses were moderately satisfied regarding their jobs (X 1/4 3.03; SD 1/4 0.95) as almost $54 \%$ nurses strongly agreed or agreed with statements concerning their job satisfaction.

\section{Testing the hypothesized model}

Measurement model: Bass [53] described modeled as secondorder latent construct with five dimensions regarding transformational leadership. Measurement model results discovered factor loadings which were acceptable for all transformational Leadership subscales (0.83e0.92). Structural empowerment was also modeled as Second order latent variable with subscales as reflective indicators. Structural empowerment subscales factor loadings were with acceptable range (0.46e 0.75). Finally, adverse events item factor loading was $(0.63 \mathrm{e} 0.71)$ and job satisfaction was within acceptable range (0.72e 0.84$)$.

Structural model: Hypothesized model supported by model fit statistics (c2=126) $1 / 4$ 267.452; p $1 / 4$ 0.001; IFI $1 / 4$ 0.962; TLI $1 / 40.955$; CFI $1 / 4$ 0.962; and RMSEA $1 / 4$ 0.052), highlighting data was good fit to the model. Significance was found between all path estimates and in direction of hypotheses. As expected, transformational leadership had significant positive, strong and direct effect (b 1/4 0.75; $\mathrm{p}<0.001$ ) (H1) upon structural empowerment, which resultantly, had positive effect on job satisfaction (b $1 / 40.84 ; \mathrm{p}<0.001)(\mathrm{H} 2)$, and had negative direct effect on adverse events $\left(b^{1 / 4} \_0.33 ; p<0.05\right)(H 3)$. Consequently, nurses job satisfaction reduced occurrence of adverse happenings $(b$ $\left.1 / 4 \_0.61 ; \mathrm{p}<0.05\right)(\mathrm{H} 4)$. Hypothesized indirect effects of structural empowerment and transformational leadership on job satisfaction and adverse events were significant (Table 3 ).

\section{Discussion}

The aim of this research was to examine the effect of transformational leadership on job satisfaction and nurse assessed adverse patient results using structural empowerment as mediating mechanism. This is the first research which provided empirical support regarding this proposition. Most important finding of this research was significant indirect effect of transformational leadership upon adverse patient outcomes through structural empowerment. Though transformational leadership provides a tangible solution to create empowering nursing work atmospheres which resultantly improves patient safety outcomes [9,54] only few researches have tested effects of transformational leadership on structural empowerment Previous researches [19,55] connecting transformational leadership with empowerment focused on psychological perspective of empowerment.

This research finding recommends that nurse managers with transformational leadership qualities enhances quality of patient care by making work atmospheres which make nurses to sense empowered for provision of best care. Similar with other researches, positive leadership styles which include behaviors of transformational leadership have been related towards patient outcomes betterment and lesser complications. For example, Higgins [5] research on Canadian nurses, established that nurses perception regarding behaviors of 


\begin{tabular}{|c|c|c|c|c|c|c|c|c|c|c|c|c|c|c|c|c|c|}
\hline \multicolumn{2}{|c|}{ Study Variable } & \multirow{2}{*}{\begin{tabular}{|l|} 
Main \\
2.04 \\
\end{tabular}} & \multirow{2}{*}{$\begin{array}{l}\text { SD } \\
0.98\end{array}$} & \multirow{2}{*}{$\begin{array}{l}\alpha \\
0.96\end{array}$} & \multirow{2}{*}{$\begin{array}{l}1 \\
-\end{array}$} & \multirow{2}{*}{$\begin{array}{l}2 \\
-\end{array}$} & \multirow{2}{*}{$\begin{array}{l}3 \\
-\end{array}$} & \multirow{2}{*}{\begin{tabular}{|l}
4 \\
-
\end{tabular}} & \multirow{2}{*}{$\begin{array}{l}5 \\
-\end{array}$} & \multirow[t]{2}{*}{6} & \multirow[t]{2}{*}{7} & \multirow{2}{*}{$\begin{array}{l} \\
-\end{array}$} & \multirow{2}{*}{$\begin{array}{l}9 \\
-\end{array}$} & \multirow{2}{*}{$\begin{array}{l}10 \\
-\end{array}$} & \multirow{2}{*}{\begin{tabular}{|l|}
11 \\
-
\end{tabular}} & \multirow{2}{*}{$\begin{array}{l}12 \\
-\end{array}$} & \multirow{2}{*}{$\begin{array}{l}13 \\
-\end{array}$} \\
\hline 1 & $\begin{array}{l}\text { Transformational } \\
\text { leadership }\end{array}$ & & & & & & & & & & & & & & & & \\
\hline 2 & $\begin{array}{l}\text { Idealized influence } \\
\text { - attribute }\end{array}$ & 2.19 & 1.04 & 0.85 & $0.90^{*}$ & - & - & - & - & - & - & - & - & - & - & - & - \\
\hline 3 & $\begin{array}{l}\text { Idealized influence } \\
\text { - behavior }\end{array}$ & 2.16 & 1.08 & 0.88 & $0.90^{*}$ & $0.80^{*}$ & - & - & - & - & - & - & - & - & - & - & - \\
\hline 4 & $\begin{array}{l}\text { Inspirational } \\
\text { motivation }\end{array}$ & 2.29 & 1.07 & 0.91 & $0.86^{*}$ & $0.73^{*}$ & $0.79^{*}$ & - & - & - & - & - & - & - & - & - & - \\
\hline 5 & $\begin{array}{l}\text { Intellectual } \\
\text { stimulation }\end{array}$ & 1.89 & 1.07 & 0.89 & $0.90^{*}$ & $0.78^{*}$ & $0.77^{*}$ & $0.73^{*}$ & - & - & - & - & - & - & - & - & - \\
\hline 6 & $\begin{array}{l}\text { Individualized } \\
\text { consideration }\end{array}$ & 1.68 & 1.18 & 0.9 & $0.88^{*}$ & $0.78^{*}$ & $0.732^{*}$ & $0.66^{*}$ & $0.80^{*}$ & - & - & - & - & - & - & - & - \\
\hline 7 & $\begin{array}{l}\text { Structural } \\
\text { empowerment }\end{array}$ & 2.99 & 0.66 & 0.82 & $0.61^{*}$ & $0.53^{*}$ & $0.56^{*}$ & $0.54^{*}$ & $0.55^{*}$ & $0.55^{*}$ & - & - & - & - & - & - & - \\
\hline 8 & Information & 3.37 & 0.97 & 0.82 & $0.28^{*}$ & $0.22^{*}$ & $0.28^{*}$ & $0.28^{*}$ & $0.26^{*}$ & $0.21^{*}$ & $0.65^{*}$ & - & - & - & - & - & - \\
\hline 9 & Support & 2.53 & 0.88 & 0.71 & $0.58^{*}$ & $0.49^{*}$ & $0.53^{*}$ & $0.52^{*}$ & $0.53^{*}$ & $0.53^{*}$ & $0.73^{*}$ & $0.35^{*}$ & - & - & - & - & - \\
\hline 10 & Resources & 2.46 & 0.87 & 0.78 & $0.50^{*}$ & $0.45^{*}$ & $0.45^{*}$ & $0.42^{*}$ & $0.45^{\star}$ & $0.47^{*}$ & $0.73^{*}$ & $0.25^{*}$ & $0.44^{*}$ & - & - & - & - \\
\hline 11 & Opportunity & 3.51 & 1.01 & 0.8 & $0.40^{*}$ & $0.35^{*}$ & $0.37^{*}$ & $0.32^{*}$ & $0.35^{*}$ & $0.38^{*}$ & $0.72^{*}$ & $0.23^{*}$ & $0.34^{*}$ & $0.44^{*}$ & - & - & - \\
\hline 12 & Job satisfaction & 3.04 & 0.96 & 0.84 & $0.56^{*}$ & $0.52^{*}$ & $0.53^{*}$ & $0.46^{*}$ & $0.49^{*}$ & $0.54^{*}$ & $0.60^{*}$ & $0.24^{*}$ & $0.40^{*}$ & $0.59^{*}$ & $0.48^{*}$ & - & - \\
\hline 13 & Adverse events & 1.82 & 0.62 & 0.78 & $-0.12 y$ & -0.09 & $-0.13^{*}$ & $-0.12 y$ & $-0.11 y$ & $-0.10 y$ & $-0.13^{*}$ & -0.1 & -0.08 & $-0.10 y$ & -0.12 & $-0.27^{*}$ & - \\
\hline \multicolumn{18}{|c|}{ Note: SD standard deviation; Cronbach alpha. } \\
\hline \multicolumn{18}{|c|}{ *: Correlation is Sinification at the, 01 level (2-tailed). } \\
\hline \multicolumn{18}{|c|}{ Y: Correlation is significant at the, 05 level (2-tailed). } \\
\hline
\end{tabular}

Table 2: Means, SDs, and Pearson's Correlations between main study variables.

\begin{tabular}{|c|c|c|c|c|c|c|}
\hline Structural Paths & & b & $\beta$ & SE & CR & p \\
\hline \multicolumn{7}{|l|}{ Indirect effects } \\
\hline $\begin{array}{l}\text { Transformational leadership } \\
\text { empowerment }\end{array}$ & Structural & 0.618 & 0.611 & 0.031 & 12.741 & $<0.001$ \\
\hline \multicolumn{7}{|l|}{ Job satisfaction } \\
\hline $\begin{array}{l}\text { Transformational leadership } \\
\text { empowerment }\end{array}$ & Structural & -0.067 & -0.137 & 0.052 & -2.571 & $<0.01$ \\
\hline \multicolumn{7}{|l|}{ Adverse patient outcomes } \\
\hline
\end{tabular}

Table 3: Total Indirect Effect of Leadership on Outcome Variables.

their managers transformational leadership had negative impact upon objectively measured adverse events (i.e., hospital infections and patient falls) through atmosphere of supportive practices and behaviors of organizational citizenship [43]. Established that leadership with authentic style was considerably related towards decrease in nurse assessed adverse happenings through faith in the manager and extents of work life. Other researches have highlighted that nursing care quality and clinical expertise are supported by transformational leadership [56]. In this research, nurses alleged their managers as moderately transformational. Particularly, component of transformational leadership, inspirational enthusiasm had strongest influence upon nurse and patient results, however lowest ranked factor was individualized consideration. Transformational leaders using inspirational motivation, convey higher expectations to employees, which motivate them to be more committed and hard working in achieving organizational goals $[13,15]$.

Transformational leaders have charismatic personality and they are also persuasive in encouraging their workers to work more than what is anticipated from them. Transformational leaders for achieving objectives provide workers a clear mission picture. They clearly define how their efforts will be fit in towards completion of organizational goals. Moreover, these leaders must address the nurses requirements by performing as coaches and mentors. They always listen and address staff concerns, and promote a supportive atmosphere for individual progress [53]. When nurses observe that their managers are giving importance to their self-progress and also empowering them in reaching their full potential, then they feel more confident and involved at work, which eventually, improve quality of patient care $[15,29]$. It is rational to believe that transformational nurse's manager may impact the occurrence of adverse happenings in their units for the reason that such leaders inspire evidence established practice and for workers to ponder regarding alternative answers for problems [15] and methods to enhance care outcomes. Leaders performing transformational leadership lay emphasis on the collaboration benefits which create values where new thinking ways are heartened and discussion is open. Such leadership empowers the nurses for solving problems [57], and take patient care responsibility which resultantly lead to fewer errors. In the present research, nurses stated modest empowerment levels in their workstation, which was alike to empowerment perceptions reported in other researches regarding nurses [58-60]. 
Results recommend that whenever nurses have accessibility to information (for example, budget clinical, quality measures and monetary information) and have influence on resources supportive practice and capability to contribute towards decisions of organization, it inspires using clinical management practices, thus enhancing the job satisfaction. Overpoweringly, the direct and strong relationship between nurses job contentment and staff empowerment highlights that increasing work quality of working atmosphere may be most vital with holding strategy. This result is also similar to previous researchers results $[60,61]$, according to which organizational empowerment effects organizational obligations and nurses' job contentment $[58,59]$, work commitment [24], lesser levels of stress and job pressure [20] and revenue intentions $[29,61]$, which completely influences nurses staffing and retention. This research finding is similar with theory of transformational leadership, which describes Leaders role in provision of employees with supportive working atmospheres results in higher work efficiency and job satisfaction [53]. After developing strong associations, transformational leaders comprehend and foresee staff requirements and make better efforts to effect resources acquisition required to enhance nurses empowerment feelings. Empowered nurses pursue new approaches for performing their job, thus improving results of patient care and generating higher job satisfaction feeling.

\section{Limitations}

The main limitation of this research is that this research is crosssectional, which limits explanation of causality to the empowerment evidence in research variables and foundational theoretical relations [62]. Longitudinal designs for examination of manager's transformational leadership and how they impact work atmosphere and patient safety results and nurse and during time must be deliberated for future study. Moreover, it is significant to highlight that other vital variables (for example, recruitment) can be added to research model for more comprehensive understanding of the impact of working environment towards quality care. In further research this aspect can be addressed. Other limitation is using self-reporting measures, which may have response bias [63].

Though, nurses secretly completed the questionnaire at their residence may have reduced prejudice by giving confidentiality and decreasing fear of punishment [63]. In this research regardless of constructs precise measurement, the assessment is either based upon perception or subjective (i.e., nurse reports are use regarding adverse patient results) symbolizes only an approximate of adverse happenings, which may result to prejudice. As a result, multisource data inclusion such as actual patient results objective ratings can reduce this threat and include too towards this research findings. Finally, though the sample taken was nurses' representative in relation to their level of education, age and experience but only $36 \%$ of respondents replied the survey. Due to expectation of low response rates usually linked with surveys by mail mainly between health care professionals [64] procedures were adopted to increase responses [38]. This research also adopted random sampling of nurses working in sensitive care hospitals to reduce potential dissimilarities among non-responders and responders.

\section{Conclusion}

In summary, the research findings underline the importance of transformational leadership in increasing the nurses work atmosphere quality for better patient outcomes. Results of this research contribute to a little but emergent body of experimental evidence presenting a relationship between patient outcomes and relational leadership. These research findings propose that transformational leadership is dominant to increase the safety of patient and enhancing satisfaction of nurses during job. Keeping in view the frequency of adverse happenings in hospitals and acute nurses shortage, it is vital that managers must adopt transformational leadership style to make sure that work atmosphere are authorizing to help nurses behaviors of professional practice for improved patient outcomes and consequently, enhanced nurse retention.

\section{References}

1. Zegers M, De Bruijne MC, Wagner C, Hoonhout LHF, Waaijman R, et al. (2009) Adverse events and potentially preventable deaths in Dutch hospitals: results of a retrospective patient record review study. BMJ Quality \& Safety 18: 297-302.

2. Donaldson MS, Corrigan JM, Kohn LT (2000) To Err is human: building a safer health system. Vol. 6. National Academies Press.

3. Baker GR, Norton PG, Flintoft V, Blais R, Brown A, et al. (2004) Canadian adverse events study. Canadian Medical Association Journal 170: 1678-1686.

4. Purdy N, Spence Laschinger HK, Finegan J, Kerr M, Olivera F (2010) Effects of work environments on nurse and patient outcomes. Journal of Nursing Management 18: 901-913.

5. Higgins EA (2015) The influence of nurse manager transformational leadership on nurse and patient outcomes: Mediating effects of supportive practice environments, organizational citizenship behaviors, patient safety culture and nurse job satisfaction, pp: 1-194.

6. Mort E, Bruckel J, Donelan K, Paine L, Rosen M, et al. (2017) Improving health care quality and patient safety through peer-to-peer assessment: demonstration project in two academic medical centers. American Journal of Medical Quality 32: $472-479$.

7. Needleman J, Buerhaus P, Mattke S, Stewart M, Zelevinsky K (2002) Nursestaffing levels and the quality of care in hospitals. New England Journal of Medicine 346: 1715-1722.

8. Cowden T, Cummings G, Profetto-Mcgrath J (2011) Leadership practices and staff nurses' intent to stay: a systematic review. Journal of Nursing Management 19: $461-477$

9. Hutchinson M, Jackson D (2013) Transformational leadership in nursing: towards a more critical interpretation. Nursing Inquiry 20: 11-22.

10. Avolio BJ, Zhu W, Koh W, Bhatia P (2004) Transformational leadership and organizational commitment: Mediating role of psychological empowerment and moderating role of structural distance. Journal of Organizational Behavior 25: 951-968.

11. Reynaldo R (2017) Healthcare Leaders under the Age of 40-Successful Strategies and Practices for Leading Healthcare Organizations. Pepperdine University, pp: 1-252

12. Schein EH (2010) Organizational culture and leadership. Vol. 2. John Wiley \& Sons.

13. Kanter RM (2008) Men and women of the corporation: New Edition. Basic Books, p: 416.

14. Yukl GA (2013) Leadership in organizations. Pearson Education India

15. Emery CR, Barker KJ (2007) The effect of transactional and transformational leadership styles on the organizational commitment and job satisfaction of customer contact personnel. Journal of Organizational Culture, Communications and Conflict 11: 77 .

16. Zhu W, Avolio BJ, Walumbwa FO (2016) Moderating role of followe characteristics with transformational leadership and follower work engagement Corrigendum. Group and Organization Management 41: 407-409.

17. Squires MAE, Tourangeau ANN, Spence Laschinger HK, Doran D (2010) The link between leadership and safety outcomes in hospitals. Journal of Nursing Management 18: 914-925.

18. Boamah SA, Read EA, Spence Laschinger HK (2017) Factors influencing new graduate nurse burnout development, job satisfaction and patient care quality: a time-lagged study. Journal of Advanced Nursing 73: 1182-1195.

19. Manojlovich M, Laschinger HKS (2002) The relationship of empowerment and selected personality characteristics to nursing job satisfaction. Journal of Nursing Administration 32: 586-595. 
Citation: Khanzada B, Naeem S, Butt H (2018) Impact of Transformational Leadership on Job Satisfaction and Patient Safety Outcomes in Health Sector of Pakistan. J Health Educ Res Dev 6: 251. doi: 10.4172/2380-5439.1000251

20. Armstrong $\mathrm{K}$, Laschinger $\mathrm{H}$, Wong $\mathrm{C}$ (2009) Workplace empowerment and magnet hospital characteristics as predictors of patient safety climate. Journal of Nursing Care Quality 24: 55-62.

21. Boamah S, Laschinger $\mathrm{H}$ (2015) Engaging new nurses: the role of psychological capital and workplace empowerment. Journal of Research in Nursing 20: 265 277

22. Wang G, Oh IS, Courtright SH, Colbert AE (2011) Transformational leadership and performance across criteria and levels: A meta-analytic review of 25 years of research. Group \& Organization Management 36: 223-270.

23. DiNapoli JM, O'Flaherty D, Musil C, Clavelle JT, Fitzpatrick JJ (2016) The relationship of clinical nurses' perceptions of structural and psychological empowerment and engagement on their unit. Journal of Nursing Administration 46: 95-100.

24. Brewer CS, Kovner CT, Greene W, Tukov-Shuser M, Djukic M (2012) Predictors of actual turnover in a national sample of newly licensed registered nurses employed inhospitals. Journal of Advanced Nursing 68: 521-538.

25. DeVivo D, Griffin MTQ, Donahue M, Fitzpatrick JJ (2013) Perceptions of empowerment among ED nurses. Journal of Emergency Nursing 39: 529-533.

26. Van Bogaert $P$, Meulemans $H$, Clarke $S$, Vermeyen $K$, Van de Heyning $P$ (2009) Hospital nurse practice environment, burnout, job outcomes and quality of care: test of a structural equation model. Journal of Advanced Nursing 65 : 2175-2185.

27. Laschinger HKS, Finegan J, Wilk $P$ (2009) Context matters: The impact of unit leadership and empowerment on nurses organizational commitment. Journal of Nursing Administration 39: 228-235.

28. Runciman WB, Baker GR, Michel P, Dovey S, Lilford RJ, et al. (2010) Tracing the foundations of a conceptual framework for a patient safety ontology. BMJ Quality \& Safety, Health Care 19: e56.

29. Cho E, Sloane DM, Kim EY, Kim S, Choi M, et al. (2015) Effects of nurse staffing work environments, and education on patient mortality: an observational study. International Journal of Nursing Studies 52: 535-542.

30. Aiken LH, Clarke SP, Sloane DM, Sochalski J, Silber JH (2002) Hospital nurse staffing and patient mortality, nurse burnout, and job dissatisfaction. JAMA 288: 1987-1993.

31. Djukic M, Kovner CT, Brewer CS, Fatehi FK, Cline DD (2013) Work environment factors other than staffing associated with nurses ratings of patient care quality. Health Care Management Review 38: 105-114

32. Hayes B, Bonner A, Pryor A (2015) Factors Contributing to Job Satisfaction in the Acute Hospital Setting: A Review of Recent Literature. Job Satisfaction, Stress and Burnout in Haemodialysis Nurses 18: 37.

33. Khamisa N, Peltzer K, Oldenburg B (2013) Burnout in relation to specific contributing factors and health outcomes among nurses: a systematic review. International Journal of Environmental Research and Public Health 10: 2214-2240.

34. Dillman DA, Smyth JD, Christian LM (2016) Internet, Phone, Mail and MixedMode Surveys: The tailored design method. Reis 154: 161-176.

35. Avolio BJ, Bass BM (2004) Multifactor Leadership Questionnaire Menlo Park CA: Mind Garden, Inc.

36. Brewer CS, Kovner CT, Djukic M, Fatehi F, Greene W, et al. (2016) Impact of transformational leadership on nurse work outcomes. Journal of Advanced Nursing 72: 2879-2893.

37. Wong CA, Laschinger HK (2013) Authentic leadership, performance, and job satisfaction: the mediating role of empowerment. Journal of Advanced Nursing 69: $947-959$

38. Attari M (2013) The Impact of Transformational Leadership on Nurse Psychological Empowerment. International Journal of Hospital Research 2: 71-76.

39. Bamford M, Wong CA, Laschinger H (2013) The influence of authentic leadership and areas of work life on work engagement of registered nurses. Journal of Nursing Management 21: 529-540.

40. Hackman JR (1980) Work redesign and motivation. Professional Psychology 11: $445-455$

41. Boev C (2012) The relationship between nurses perception of work environment and patient satisfaction in adult critical care. Journal of Nursing Scholarship 44: 368-375.
42. Wagner III WE (2014) Using IBM $®$ SPSS $®$ statistics for research methods and social science statistics. Sage Publications.

43. Arbuckle James L (2012) IBM SPSS Amos 21 User's Guide. IBM, USA

44. Preacher KJ, Hayes AF (2008) Asymptotic and resampling strategies for assessing and comparing indirect effects in multiple mediator models. Behavior Research Methods 40: 879-891.

45. Lin SH, Hsieh PJ (2010) Book Review: Kline RB. Principles and Practice of Structural Equation Modeling. New York: Guilford, p: 366. Research on Social Work Practice 20: 126-128.

46. Bentler PM (1990) Comparative fit indexes in structural models. Psychological Bulletin 107: 238-246.

47. McArdle JJ (2011) Some ethical issues in factor analysis. Handbook of ethics in quantitative methodology p: 313

48. Muthén LK, Muthén BO (2010) Mplus: Statistical analysis with latent variables: User's guide, pp: 1998-2007.

49. Bass BM, Avolio BJ, Jung DI, Berson Y (2003) Predicting unit performance by assessing transformational and transactional leadership. Journal of Applied Psychology 88: 207-218.

50. Page A (2004) Keeping patients safe: Transforming the work environment of nurses. National Academies Press.

51. Chiok Foong Loke J (2001) Leadership behaviours: effects on job satisfaction productivity and organizational commitment. Journal of Nursing Management 9: 191-204.

52. Kleinman C (2004) The relationship between managerial leadership behaviors and staff nurse retention. Hospital Topics 82: 2-9.

53. Cook MJ (2001) The attributes of effective clinical nurse leaders. Nursing Standard 15: 33-36.

54. Smith L, Andrusyszyn MA, Spence Laschinger HK (2010) Effects of workplace incivility and empowerment on newly-graduated nurses' organizational commitment. Journal of Nursing Management 18: 1004-1015.

55. Laschinger HKS (2008) Effect of empowerment on professional practice environments, work satisfaction, and patient care quality: Further testing the nursing work life model. Journal of Nursing Care Quality 23: 322-330.

56. Stam L (2012) Linking Psychological Capital, Structural Empowerment and Perceived Staffing Adequacy to New Graduate Nurses' Job Satisfaction, pp $1-72$.

57. Ning S, Zhong H, Libo W, Qiujie L (2009) The impact of nurse empowerment on job satisfaction. Journal of Advanced Nursing 65: 2642-2648.

58. Graneheim UH, Lundman B (2004) Qualitative content analysis in nursing research: concepts, procedures and measures to achieve trustworthiness. Nurse Education Today 24: 105-112.

59. Podsakoff PM, MacKenzie SB, Lee JY, Podsakoff NP (2003) Common method biases in behavioral research: $A$ critical review of the literature and recommended remedies. Journal of Applied Psychology 88: 879.

60. Dykema J, Jones NR, Piche T, Stevenson J (2013) Surveying clinicians by web: current issues in design and administration. Evaluation \& the Health Professions 36: 352-381.

61. Armstrong KJ, Laschinger H (2006) Structural empowerment, Magnet hospita characteristics, and patient safety culture: making the link. Journal of Nursing Care Quality 21: 124-132.

62. Boamah SA, Laschinger HKS, Wong C, Clarke S (2017) Effect of transformational leadership on job satisfaction and patient safety outcomes. Nursing Outlook, pp: 30274-30279.

63. Kovner C, Jones C, Zhan C, Gergen PJ, Basu J (2002) Nurse staffing and postsurgical adverse events: an analysis of administrative data from a sample of US hospitals, 1990-1996. Health Services Research 37: 611-629.

64. Sochalski J, Estabrooks CA, Humphrey CK (2009) Nurse staffing and patient outcomes: evolution of an international study. CJNR (Canadian Journal of Nursing Research) 41: 320-339. 